\title{
An Investigation Report of the Status Quo and Training Demands of Rural Primary English Teachers in North Anhui Province
}

\author{
Zhao Guangcun ${ }^{1}$ \\ ${ }^{1}$ Center for Foreign Literature and Culture, Guangdong University of Foreign Studies, China \\ Correspondence: Zhao Guangcun, Center for Foreign Literature and Culture, Guangdong University of Foreign \\ Studies, China.
}

Received: September 28, 2018

Accepted: November 2, 2018 Online Published: November 6, 2018

doi: $10.5539 /$ elt.v11n12p38

URL: https://doi.org/10.5539/elt.v11n12p38

\begin{abstract}
Through questionnaires and statistical analysis, it is found that the status quo and training needs of rural primary English teachers in northern Anhui Province are as follows: (1) Teachers are young, female and hold concurrent posts in English teaching; (2) Most teachers have a strong desire to participate in the training, but fail to do so due to heavy workload of the course, or lack of the opportunity to go out to participate in higher level training; (3) Their ideal trainers are excellent front-line English teachers, and eager to get trained in education concepts, teaching skills and technology, and teaching modes. They are not interested in the study of education theory or academic research; (4) Many teachers lack confidence in their competence and urgently need training in their basic skills. In view of the above results, countermeasures are put forward as follows: to speed up the transformation of teachers' growth, strengthening teachers' basic skills of teaching, teaching while conducting scientific research, and combining field training and remote training together.
\end{abstract}

Keywords: rural primary English teachers, status quo of teachers' quality, training demands

\section{Introduction}

In 2001, the Ministry of Education promulgated the English Curriculum Standards (experimental draft) for full-time compulsory courses (New Curriculum Standard for short). From the autumn of 2001, English courses were gradually offered in primary schools in cities and counties throughout the country. In the autumn of 2002, English courses were gradually offered in primary schools located in rural schools (Fu, 2013). From 2001 to 2008, the average opening rate of English in primary schools in China has reached 60-70\%, and in many large and medium-sized cities it has reached $100 \%$. Teachers are the main force in curriculum reform, and their education concept and teaching professional level will undoubtedly become the key to curriculum reform (Wang, 2008). In order to have a more objective and comprehensive understanding of the current situation and training needs of English teachers in rural primary schools in North Anhui Province, this study conducted a questionnaire survey on 426 rural primary teachers in North Anhui Province (Bozhou City and Fuyang City as an example) in four aspects, namely, basic individual information, basic training-participation information, demands of training methods and demands of training content.

This study started in December 2016 and was completed in June 2017. A total of 440 copies of the questionnaires were issued (including electronic and paper questionnaires), and 431 copies were recovered, among which 5 copies of the questionnaires were abandoned due to non-compliance of answering standards (such as multiple choices of the single-choice questions, single choice of multiple-choice questions, or missing two or more questions, or the electronic questionnaires unable to be opened or without being answered due to technical problems). In the end, there were 426 copies of valid questionnaires left, with a recovery rate of $96.8 \%$.

\section{Questions and Discussions}

\subsection{Basic Individual Information}

This part contains six questions, including gender, age, teaching experience, education background, major and professional title. 
Table 1. Basic individual information

\begin{tabular}{llllll}
\hline Item & Gender & Age & Teaching Experience & Education Background & Major \\
\hline \multirow{2}{*}{ A/Percentage } & Male & Under25 & $0-3$ Years & Teachers' Normal School & English \\
& $114 / 26.8$ & $114 / 26.8$ & $186 / 43.7$ & $6 / 1.4$ & $237 / 55.6$ \\
B/Percentage & Female & $26-34$ & $4-9$ Years & Professional College 171/40.1 & Others \\
& $312 / 73.2$ & $198 / 46.5$ & $129 / 30.3$ & & \\
C/Percentage & & $35-44$ & Over10 Years & College & \\
& & $81 / 19.0$ & $111 / 26.0$ & $249 / 58.5$ & \\
D/Percentage & & Over45 & & Others & \\
Sum/Percentage & $426 / 100$ & $43 / 7.7$ & & $0 / 0$ & $426 / 100$ \\
\hline
\end{tabular}

Table 1 indicates as follows: (1) In the respect of gender and age, the percentage of women is far higher than that of men, almost three times as high. In terms of age distribution, teachers aged 26-34 years were the most (46.5\%), followed by young teachers aged under 25 years $(26.8 \%)$, and teachers aged 35-44 years also account for a large proportion. (2) In terms of teaching experience and education background, the number of teachers who have just graduated is the largest $(43.7 \%)$, followed by teachers of $4-9$ years $(30.3 \%)$. Undergraduates are the most $(58.5 \%)$, followed by technical college students $(40.1 \%)$. (3) In terms of majors and professional titles, nearly half of primary school English teachers are teachers of non-English majors (44.4\%). There are many teachers of first level professional certificates $(29.6 \%)$ and secondary level $(23.6 \%)$. Senior teachers account for a certain proportion (14.1\%).

The above results indicate that the features of rural primary school English teachers are as follows: mainly female, the majority of them are young teachers who have just graduated, relatively high education level (mostly graduating from professional colleges or colleges), more teachers with first level professional certificates (generally teaches need at least 4 years to be promoted to such a level), the phenomena of non-English teachers teaching English and junior high school English teachers teaching English in primary schools. Young teachers who have just graduated lack of experience, and they have not yet formed a mature and effective teaching style and mode, still trying to find a suitable teaching method. Non-English teachers teaching English and middle school teachers teaching primary school English is a very serious phenomenon in rural primary school English teaching. The former is simply a layman, most likely to mislead the children; The latter seems "condescending" and "over adequate" to teach primary school English, but due to the great differences between primary and junior high school students, junior high school teachers cannot be fully qualified for primary school English teaching.

\subsection{Basic Training- participation Information}

There are 9 questions on the basic training-participation information, including, desire of training-participation, training levels the subjects have participated in, which form of training they have frequently participated in, purposes of training-participation, obstacles of training-participation, main reasons for their reluctance of training-participation, regular teaching and research activities, ways of accessing to information and current dreams.

Table 2. Subjects' basic training-participation information

\begin{tabular}{llllllll}
\hline Item & Desire & Level & Form & Purpose & Obstacle & Reluctance & Activities \\
\hline A/ & Strong & National & New & Edu. Concept & No Time & Unnecessary & Open \\
Percent. & $174 / 40.8$ & $57 / 11.8$ & Curricula & $315 / 66.9$ & & $36 / 5.6$ & Classes \\
& & & $153 / 35.9$ & & $252 / 56.4$ & & $405 / 50.9$ \\
B/ & Interested & Provincial & Core & Prof. Title & Economic & Too Busy & Project \\
Percent. & $159 / 37.3$ & $81 / 16.8$ & Teachers & Promotion & Burden & & Experiment \\
& & & $69 / 16.2$ & $27 / 5.7$ & $39 / 8.7$ & $330 / 50.9$ & $39 / 4.9$
\end{tabular}




\begin{tabular}{|c|c|c|c|c|c|c|c|}
\hline $\mathrm{C} /$ & So-so & Prefecture & Edu. & Leaders’ & Leaders' & Titles & Compiling \\
\hline Percent. & $78 / 18.3$ & $105 / 21.7$ & $\begin{array}{l}\text { Tech. } \\
138 / 32.4\end{array}$ & $\begin{array}{l}\text { Requirement } \\
27 / 5.7\end{array}$ & $\begin{array}{l}\text { Neglect } \\
24 / 5.4\end{array}$ & $\begin{array}{l}\text { Promoted } \\
27 / 4.2\end{array}$ & $\begin{array}{l}\text { School-based } \\
\text { Courses } \\
60 / 7.5\end{array}$ \\
\hline $\mathrm{D} /$ & Unwilling & County & Others & Continuing & Others & Occupying & Group \\
\hline Percent. & & $180 / 37.3$ & & Edu. Task & $132 / 29.5$ & Leisure & Lesson \\
\hline & $15 / 3.5$ & & $66 / 15.5$ & $102 / 21.7$ & & Time & Preparation \\
\hline & & & & & & $222 / 34.3$ & $291 / 36.6$ \\
\hline $\mathrm{E} /$ & & Never & & & & Self- & \\
\hline Percent. & & $60 / 12.4$ & & & & Paying & \\
\hline & & & & & & $33 / 5.1$ & \\
\hline
\end{tabular}

Sum/

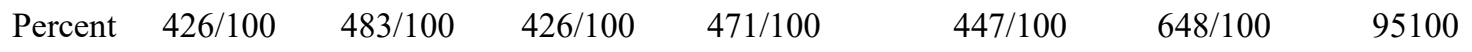

Notes: Percent. referring to Percentage; Edu. referring to Education; Tech. referring to technology; Prof. referring to professional.

The results show that: (1) $78.1 \%$ of the teachers are willing to participate in training, and nearly half (49\%) of the respondents choose prefectural and county levels of training, while only $28.6 \%$ of the respondents choose national and provincial training, and a considerable number (12.4\%) have never participated in training. (2) Participation frequency and purpose: in the column of "which form of training has the most number of participants", "new curriculum standards, new teaching material teaching method training" and "modern education technology training" account for $68.3 \%$, while only $16.2 \%$ participate in backbone teachers' training. In the column of "the purpose of training" with $66.9 \%$ of the teachers choose "to accept the new teaching concept, acquire new knowledge and new skills". Of course, a part of the teachers' participation in training is forced and passive, in order to meet leaders' requirement, or to complete tasks of continuing education. Their participation initiative is not high, with $5.7 \%$ of the teachers' participation in training aimed to be promoted to a higher professional title. (3) Reasons for participation obstacles and non-participation: in the column of "the biggest obstacle for you to participate in the teacher training" and "the main reasons for your reluctance to participate in the training", more than half of the teachers choose no time and too busy. In addition, 29.3 percent of the respondents choose "others" as the biggest obstacle to participating in teacher training. (4) Participating in teaching and research activities: $87.5 \%$ of the teachers choose the two items of "colleagues attending lectures, reviewing lessons, lecturing" and "group preparing for lessons" in the answer to "your frequently-participated teaching and research activities". Those who participate or engage in the project experiment $(4.9 \%)$ and conduct the school-based curriculum compilation and development (7.5\%) are fewer. (5) Access to information and current aspirations: in the column of "access to new information", more than $1 / 3$ choose "searching online", more than $1 / 3$ use books and magazines, and nearly $1 / 3$ chooses "asking colleagues and others". As for "current aspirations", $71 \%$ of the teachers choose "to become prominent teachers, enabling students to learn well and taking part in professional studies to constantly improve their professional quality" Some teachers also choose "transferring from teachers' jobs" (5.2\%).

The above results show that more than $70 \%$ of the teachers investigated are willing to participate in the training to improve their professional quality and become excellent teachers. They are willing to participate in training to improve education concept, acquire new knowledge and skills, and improve education technical means. However, most teachers are unable to participate in the training due to the heavy burden of schoolwork and lack of time. There are quite a few teachers who lack the initiative to participate in training and further education. They are forced to learn passively. The level that the teacher attends teaching research and training is not high, mostly in the school, within the town, or city level at most.

\subsection{Demands of Training Methods}

There are 4 questions in this part. The survey is conducted from 4 aspects: the most effective training form, ideal trainer, favorite training teaching form, and assessment method. 
Table 3. Information of demands of training methods

\begin{tabular}{lllll}
\hline Item & Training Form & $\begin{array}{l}\text { Ideal } \\
\text { Trainer }\end{array}$ & Teaching Form & Assessment Method \\
\hline A/ & Teaching Theory & $\begin{array}{l}\text { Instructor/ } \\
\text { Researcher }\end{array}$ & Seminar & Examination \\
Percent. & $168 / 15.5$ & $141 / 16.4$ & $126 / 10.8$ & $114 / 14.7$ \\
& & Outstanding & Lecturing/ Self-study & Assignment \\
B/ Percent. & Technique/ Skill & Teacher & $228 / 19.5$ & Completion \\
& $330 / 30.4$ & $399 / 46.5$ & Observation/ & Paper Submission \\
& Expert & Professor/ Expert & Discussion & $81 / 10.4$ \\
C/ Percent. & Lecture & $201 / 23.4$ & $276 / 23.7$ & Training \\
& $222 / 20.4$ & Theory Researcher & Peer & Writing \\
& Demonstration & & Communication \\
D/ Percent. & Class & $117 / 13.6$ & $255 / 21.9$ & $282 / 36.3$ \\
& $366 / 33.7$ & & Expert Comment & \\
E/ Percent. & & & $174 / 14.9$ & \\
& & & Remote Seminar & \\
F/ Percent. & & & $87 / 7.5$ & \\
G/ Percent. & & & Others & \\
Sum/ & & & $21 / 1.8$ & \\
Percent. & $1086 / 100$ & & $1167 / 100$ & \\
\hline
\end{tabular}

The above results indicate that: (1) Training form: the teachers investigated consider "education and teaching professional skills, modern education technology" (30.4\%) and "quality class observation" (33.7\%) as the most effective training form, followed by "experts and professors' lectures" (20.4\%) and "English teaching theory" $(15.5 \%)$; (2) Ideal trainers: nearly half $(46.5 \%)$ of the subjects choose outstanding teachers, followed by "professors and experts with higher academic level", "English teachers and researchers" and "theory researchers in education scientific research department"; (3) Training teaching form: in answering "the most popular form of training teaching", "group observing and discussion" account to $23.7 \%$, followed by "peer experience, discussion, mutual discussion" (21.9\%). In addition, "the combination of lecturing and self-study", "experts' on-site review guide", and "expert systematic seminars" also takes a lot of proportion (45.2\%). At the same time, there are $7.5 \%$ of subjects choosing the "network remote seminar"; (4) Assessment method: $74.9 \%$ of the subjects choose "assignment completion of the training course" and "writing training experience", followed by "examination" (14.7\%). However, only $10.4 \%$ chose "paper submission".

In conclusion, the survey results of training method demands show that most of the subjects want to learn practical things like education concept, teaching skills, technology and teaching modes. In their mind, the most ideal trainer is a first-line excellent English teacher, or a professor expert. In addition, they have shown some interest and expectation in teaching theories and expert lectures. Their favorite form of training teaching is "group discussion, observation, peer experience introduction, exchange discussion, joint discussion", which can greatly mobilize their participation enthusiasm and improve each other. Moreover, due to the subjects' disadvantage of lack of theory quality, more people choose the familiar and confident assessment method, while showing great fear for paper writing.

\subsection{Demands of Training Content}

This part consists of 5 questions, including 5 aspects: "whether I have seen the course standards and the interpretation of it", "what is the required English language proficiency training", "whether I am qualified for the 
current teaching work", the expectation of participating in the training, and "the training topic I hope to participate in".

Table 4. Demands of training content

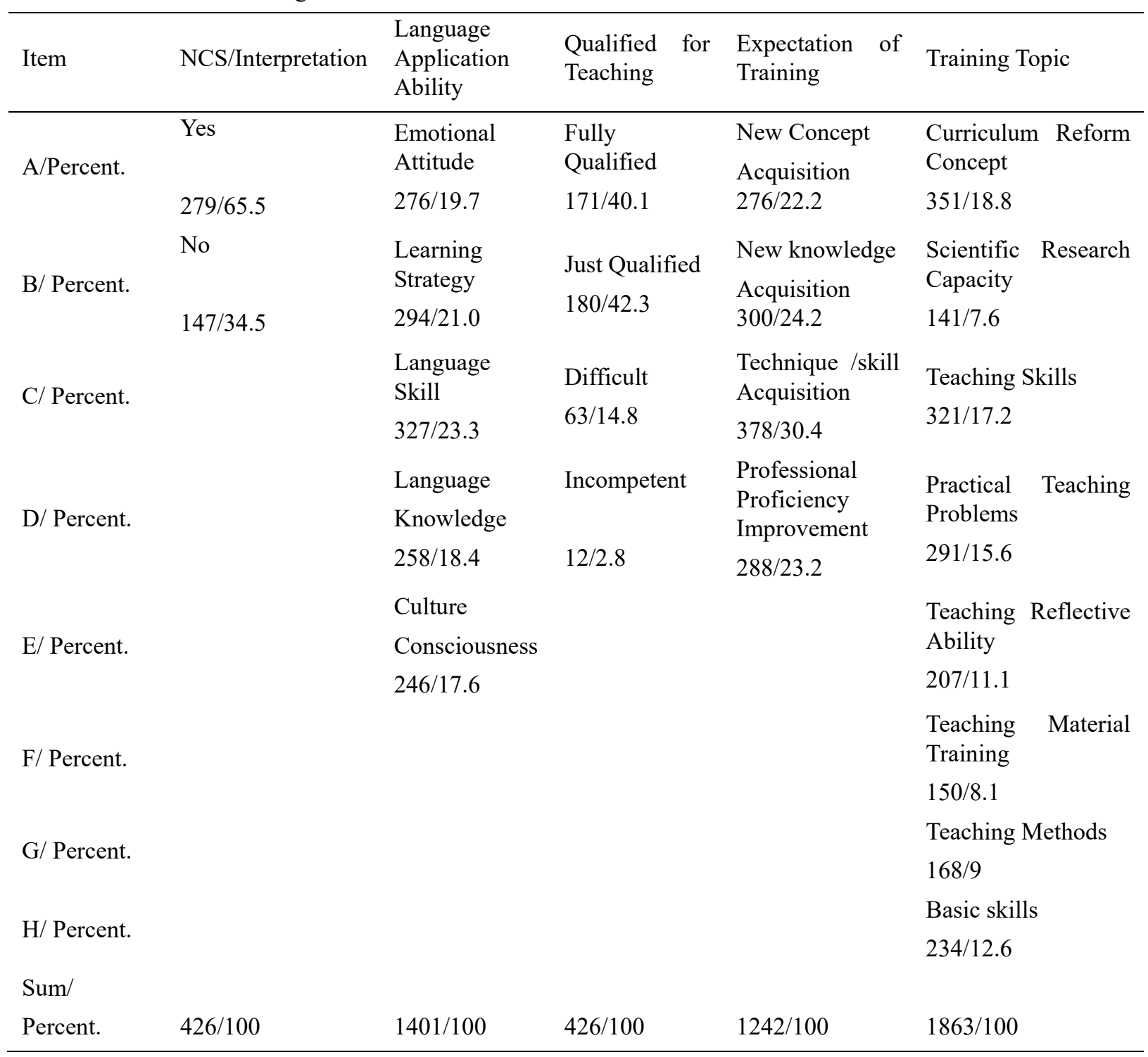

The results show that: (1) Learning of curriculum standards: nearly two-thirds (65.5\%) have read "English curriculum standards and interpretation of curriculum standards", and about one-third (34.5\%) have not; (2) Required English language skills: five items are basically equal in their choice, only "language knowledge" and "language skills" are slightly higher; (3) Qualified for teaching: $40.1 \%$ of the subjects show great confidence, indicating "totally ok"; $42.3 \%$ of the responses are "just right", showing a bit of diffidence; nearly 18 percent of the participants show a sense of incompetence in their work; (4) Expectation of participating in training: "some effective skills or techniques for adapting to work" accounts for 30.4\%, while the other three are roughly equal; (5) Training topic: "training to improve scientific research ability" and "education teaching and research ability" have the lowest scores ( $7.6 \%$ and $9.1 \%$, respectively); "lecturing and public classes" have the highest scores (29.1\%), followed by "group lesson preparation and grinding" $(27 \%)$, then is the choice "teaching case analysis" (24.9\%).

The above results show that most teachers can carefully study the curriculum standards and the interpretation of the curriculum standards, and master their key spirit to guide their own education teaching. There are quite a few teachers who have no confidence in their ability to teach. They are in urgent need of improving their language 
knowledge and language skills, cultivating positive emotional attitudes, accepting new ideas and knowledge, and receiving training in improving teaching skills and techniques. They expect to improve themselves in the design of teaching steps, such as classroom organization and management ability, teaching design ability, implementation of teaching design ability, teaching evaluation ability, etc. Their favorite teaching and research methods are lecturing, taking public classes, preparing lessons collectively, and teaching case analysis, because these are closely related to the actual teaching and can better solve the problems encountered by teachers in the teaching process. As for the improvement of scientific research ability, only a few teachers are interested.

\section{Suggestions}

\subsection{Accelerating the Transformation of Teachers' Growth}

Most primary school English teachers are young teachers under the age of 34, and most of them are female. Their education background is mostly special education or undergraduate education, the professional title is mostly first or secondary level, and some teachers are non-English teachers teaching English or part-time English teachers. Some teachers are junior middle school teachers changing to teach primary school English. First of all, the growth of female teachers is the most important concern. Especially for female teachers who have a family, they spend a lot of time on housework and have no time to study. Therefore, it is necessary for them to use the winter and summer vacation to participate in professional knowledge and skills training. Second, fresh graduates of young teachers have not yet behaved well on the platform. It can be said that they are ambitious and passionate, but do not know where to go. They are eager to grow, and at this time, they most need to have a "mentor" to guide them, and need a platform like backbone-teacher training to improve them. During the training, through the process of watching, listening, acting, practicing, discussing and thinking, they constantly build a system of integrating theory and practice of English teaching in primary school, thus to guide their own teaching work, so that they will gradually find a suitable teaching path. For those teachers who have already crossed such a stage, they also need to receive regular training to keep pace with the times, and get improved to a higher level. After that, teachers who are not English majors who teach English classes, or changing to teach English midway, or teachers who teach English classes in primary schools from junior middle schools, need to receive formal professional training. Their relevant professional knowledge of English education need to be popularized and strengthened, so that they can master the basic English teaching skills of primary schools, and can successfully transform themselves into qualified primary English teachers.

\subsection{Strengthening the Basic Skills of Teachers}

The basic skills of teachers are the embodiment of the basic qualities of teachers, or called the professional skills of teachers. As the name implies, it is the teaching ability and quality that meet the requirements of the profession in the teaching, and should achieve "high quality, profound knowledge, solid foundation and versatile". A qualified English teacher should not only master solid education teaching theory and professional knowledge, but also have good English teaching skills. To be specific, it is necessary to comprehensively consolidate the basic skills of teachers. It includes: improving language knowledge and language skills, cultivating positive emotional attitudes, mastering scientific and effective learning strategies, and enhancing cross-cultural awareness; strengthening the design and guidance of teaching steps, such as lesson preparation, class teaching, classroom activity design, teacher-student interaction, homework grading, assessment and evaluation, as well as the training of teaching skills, such as listening, speaking, reading, writing, translating, playing games, stick painting, story-telling, English song performance, teaching tool making, courseware making, etc. Therefore, in the training, we should invite more outstanding teachers, such as primary school English backbone teachers, teaching experts, teaching stars, famous teachers, or the winners of the national English teaching or teaching design competition to give lessons to the trainees.

\subsection{Combining Teaching and Scientific Research}

Teachers should not only be confined to be "teachers", but also try to "scholars" and "masters". The scientific research takes the teaching as the platform, the test base, and the scientific research achievement in turn guides the teaching practice, both of which cannot be neglected. Yuan (2006: 61) also summarized ten professional abilities that a teacher should have: cognitive ability, teaching reflection ability, design creativity ability, execution ability, observation ability, discourse ability, interaction ability, group control ability, presentation and operation ability, research ability. As a kind of professional ability of teachers, research ability is listed separately, which shows its importance. In addition, these ten aspects are the entry point and research perspective of teachers' academic research. Therefore, if a teacher wants to go further on his or her own professional path, he or she must have profound professional theoretical accomplishment, and elevate his or her successful teaching practices and thoughts to the height of theory, and then guide his or her practice with the theory. Teachers should 
be encouraged to read, read, think, write and practice more. Over time, it will develop a more acute insight and a strong academic sensitivity. From doing small projects and solving small problems, to doing big projects and solving complex problems, the ability of scientific research will be greatly improved.

\subsection{Combining On-site and Remote Training}

Short-term training is not enough to completely change the status quo of teachers. Maybe it can only stimulate their thinking, help them understand new teaching concepts, and familiarize them with new teaching models, etc. But to fundamentally improve their teaching quality and teaching skills, it is necessary to combine on-site training with remote tracking guidance. Follow-up guidance should be followed after the training. Ensure trainee teachers to apply the ideas and methods they learned to their practical teaching to improve their professional level Make use of network technology platform for communication, such as Micro blog attention, QQ groups, WeChat groups, email boxes and other methods that can maintain long-term contact with the trainees, and conduct online communication activities with hot issues to promote the teaching ability of key English teachers in primary schools. In the process of tracking, they can find the trainees' problems in teaching timely, help them analyze and solve problems enthusiastically, improve their ability to reflect and solve problems, and keep the sustainable development of teachers' quality.

\section{Conclusion}

This paper mainly uses the form of questionnaire survey, conducting the investigation of the 426 rural primary school English teachers in North Anhui Province in four aspects, namely basic individual information, basic training-participation information, demands of training methods, and demands of training content. By analyzing and discussion, we reach the following conclusions: (1) The phenomenon of most teachers being young and feminine, and non-English majors and junior high school English teachers teaching primary school English is very common; (2) Most teachers have strong willingness to participate in training, but they are unable to participate in training due to heavy workload or lack of opportunities to participate in higher-level training outside the school; (3) The teacher's ideal trainer is a first-line excellent English teacher, who wants to train education concept, teaching skills, technology and teaching mode, but is not interested in studying education theory and conducting academic research; (4) Many teachers lack confidence about whether they are qualified for their jobs and are in urgent need of basic skills training. In view of the above research results, to improve the quality of rural primary school English teachers in North Anhui Province, the author proposed four targeted countermeasures, i.e. accelerating the transformation of teachers' growth, strengthening the basic skills of teachers, combining teaching and scientific research, and combining on-site and remote training.

The paper still has several limitations. Firstly, the sample size is still small. In the cities of Bozhou and Fuyang, there are still quite a large number of rural primary English teachers who are not investigated. In the further study, more teachers representing different parts of the two regions should be taken into consideration. Secondly, a combined method should be used, i.e. besides questionnaires, interviews and observations should be utilized to collect more first-hand data. Thirdly, whether the questionnaire is valid or reliable is still a question. The questionnaire should be refined and bettered in the future study.

\section{References}

$\mathrm{Fu}, \mathrm{M}$. (2012). Training of English teachers in rural primary schools under the background of new curriculum reform. Xi 'an Social Science, 31(02), 149-150.

Wang, Q. (2008). Solving difficulties in English curriculum reform by means of reform. China Education, 09-12(005).

Yuan, C. W. (2006). New curriculum classroom teaching design series: new curriculum primary school English classroom teaching design. Beijing: People's Education Press.

\section{Copyrights}

Copyright for this article is retained by the author(s), with first publication rights granted to the journal.

This is an open-access article distributed under the terms and conditions of the Creative Commons Attribution license (http://creativecommons.org/licenses/by/4.0/). 